DOI: https://doi.org/10.24127/ajpm.v10i3.3735

\title{
KARAKTERISTIK MISKONSEPSI MAHASISWA PADA KONSEP HIMPUNAN DITINJAU DARI KEMAMPUANNYA DALAM MENGKONSTRUKSI BUKTI MATEMATIS
}

\author{
Arif Hidayatul Khusna ${ }^{1}$, Alfiani Athma Putri Rosyadi ${ }^{2}$ \\ ${ }^{1 *, 2}$ Pendidikan Matematika, Universitas Muhammadiyah Malang, Malang, Indonesia \\ *Corresponding author. Universitas Muhammadiyah Malang, Malang, Indonesia \\ E-mail: $\quad \underline{\text { khusna@umm.ac.id }}^{\left.{ }^{*}\right)}$
}

Received 20 May 2021; Received in revised form 09 September 2021; Accepted 26 September 2021

\begin{abstract}
Abstrak
Salah satu hal yang mempengaruhi mahasiswa melakukan kesalahan pada materi himpunan adalah belum mahirnya kemampuan dalam membuktikan.Tujuan dari penelitian ini adalah untuk mendiskripsikan miskonsepsi mahasiswa pada konsep himpunan ditinjau dari kemampuannya dalam mengkonstruksi bukti. Penelitian ini merupakan penelitian deskriptif dengan pendekatan kualitatif. Instrumen yang digunakan adalah tes untuk memperoleh data miskonsepsi, dan pedoman wawancara untuk mendukung temuan miskonsepsi pada instrument tes. Hasil penelitian menunjukkan bahwa pada kriteria general argument miskonsepsi yang tejadi adalah ketidaksesuaian penafsiran konsep himpunan kosong dengan makna konsep himpunan kosong yang sebenarnya serta ketidak akuratan konsep subset yang dipahami. Pada subjek invalid general argument mengalami miskonsepsi berupa ketidak akuratan dalam memahami konsep anggota himpunan dan subset. Miskonsepsi yang terjadi pada subjek empirical argument adalah ketidak tepatan dalam menghubungkan konsep himpunan dan himpunan kosong, ketidaktepatan dalam mendiskripsikan makna simbol himpunan kosong, dan ketidak akuratan pada konsep subset. Sedangkan pada subjek non genuine argument miskonsepsi berupa ketidak tepatan dalam menafsirkan konsep anggota himpunan serta tidak dapat menghubungkan konsep negasi implikasi pada definisi subset, dan ketidaktepatan dalam memaknai simbol himpunan kosong.
\end{abstract}

Kata kunci: Himpunan; mengkonstruksi bukti matematis; miskonsepsi.

\begin{abstract}
Misconception is a misunderstanding caused by thoughts that are not based on precise information. The purpose of this study was to describe students' misconceptions on set concepts in terms of their ability to construct evidence. This research is a descriptive study with a qualitative approach. The instrument used was a test to obtain misconception data, and an interview guide to support the findings of misconceptions on the test instrument. The results showed that the criteria for general argument misconceptions that occurred were inconsistencies in the interpretation of the empty set concept with the actual meaning of the empty set concept and the inaccuracy of the understood subset concept. In the invalid general argument subject, there is a misconception in the form of inaccuracy in understanding the concept of set members and subsets. The misconceptions that occur in the subject of the empirical argument are the inaccuracies in connecting the concept of the empty set and the empty set, the inaccuracy in describing the meaning of the empty set symbol, and the inaccuracy in the concept of the subset. Whereas in the subject of non genuine arguments, misconceptions were in the form of inaccuracies in interpreting the concept of set members and unable to connect the concept of negation implications in the definition of subsets, and inaccuracies in interpreting the empty set symbols.
\end{abstract}

Keywords: Constructs mathematical proofs; misconceptions; sets.

This is an open access article under the Creative Commons Attribution 4.0 International License 


\section{PENDAHULUAN}

Karakter pengetahuan matematika itu bersifat abstrak (Aydin et al., 2017)(Özdemir, Karaşan, \& Şahal, 2021). Sifat abstrak inilah yang menyebabkan matematika diajarkan secara berjenjang dimulai dari tahapan yang sederhana hingga kompleks (Tang, Tsai, \& Huang, 2020). Dari yang bersifat kongkrit, semi abstrak menuju pada pengetahuan abstrak (GoldinMeadow, 2015). Pengetahuan matematika terbagi menjadi dua yaitu pengetahuan konseptual dan prosedural (Hallett, Nunes, \& Bryant, 2010). Pada teori pendekatan instruksional konstruktivis lebih ditekankan pada pengetahuan konseptual (Lui \& Bonner, 2016). Pengetahuan konseptual ini melibatkan kemampuan dalam memahami suatu konsep serta memahami hubungan antar konsep satu dengan konsep lain dalam matematika (Ma, 2010). Karena karakter matematika yang bersifat hirarkis yaitu adanya keterkaitan antar satu konsep dengan konsep lainnya, akan sangat fatal jika terjadi kegagalan dalam memahami suatu konsep. Kegagalan memahami suatu konsep inilah yang disebut miskonsepsi.

Miskonsepsi

adalah

kesalahpahaman yang disebabkan adanya pemikiran yang tidak didasarkan pada informasi yang tepat. Miskonsepsi dapat juga diartikan sebagai ketidaksesuaian pandangan seseorang dengan padangan ilmiah (Arslan, Cigdemoglu, \& Moseley, 2012). (Lucariello, Tine, \& Ganley, 2014) (Ay, 2017) menyatakan bahwa miskonsepsi merupakan hambatan dalam proses asimilasi konsep yang benar. Miskonsepsi atau kesalahpahaman ini bermula dari konsep yang dibentuk secara mandiri melalui proses penalaran, intuisi, dan budaya sekitar, tetapi konsep tersebut berbeda dengan konsep yang sebenarnya (Ningrum, Yulianti, Helingo, \& Budiarto, 2018) (Ojose, 2015). (Cetner, 2016) menyatakan bahwa miskonsepsi disebabkan kebutuhan siswa yang berlebihan untuk memahami petunjuk yang mereka terima. Dalam beberapa kasus miskonsepsi dapat bertahan lama dalam pemikiran siswa dikarenakan siswa mengingat konsep yang salah dalam waktu yang lama (Hayati \& Setyaningrum, 2019).

Kemampuan mengkonstruksi bukti merupakan salah satu kemampuan yang harus dikuasai dalam mempelajari matematika karena matematika berisi definisi, teorema, aksioma yang melibatkan proses pembuktian. Kemampuan mengkonstruksi bukti diperlukan agar mahasiswa terlatih dalam mengkomunikasikan ide-ide matematika secara logis sehingga menghasilkan pengetahuan matematika baru yang sistematis (Steele \& Rogers, 2012). Terdapat empat kategori model pengkonstruksian bukti matematis yaitu (1) general argument yang berarti mengkonstruksi bukti melalui pengurutan pernyataan yang mengacu pada semua kasus yang sebelumnya, (2) invalid general argument yaitu proses pembuktian masih lemah, (3) empirical argument yaitu proses pembuktian menggunakan beberapa kasus yang sesuai, dan (4) non genuine argument dengan hanya sebatas mempercayai pernyataan (Stylianides \& Stylianides, 2009). Meskipun kemampuan mengkonstruksi bukti ini penting, hasil penelitian (Inglis \& Alcock, 2012) (Mejia-Ramos \& Weber, 2014) menunjukkan bahwa sebagian besar mahasiswa tidak dapat membedakan proses pembuktian yang valid dan tidak valid. 
Himpunan merupakan konsep dasar yang harus dipahami sebelum mempelajari lebih lanjut konsep-konsep lain yang ada dimatematika. Beberapa penelitian telah dilakukan terkait miskonsepsi yang terjadi pada konsep himpunan. Hasil penelitian (Kolitsoe Moru \& Qhobela, 2013) menunjukkan mahasiswa mengalami miskonsepsi pada konsep himpunan kosong, operasi gabungan, dan himpunan berhingga. Selain itu hasil penelitian (Lestyanto et al., 2019) mahasiswa juga mengalami miskonsepsi pada konsep subset, power set dan makna beberapa simbol yang berkaitan dengan himpunan. (Andriani, 2019) menyatakan bahwa salah satu hal yang mempengaruhi mahasiswa melakukan kesalahan pada materi himpunan adalah belum mahirnya kemampuan dalam membuktikan. Pengaruh ini perlu diteliti lebih dalam untuk melihat sejauh mana miskonsepsi yang siswa lakukan dengan melihat kemampuan mereka dalam mengkonstruksi bukti. Sehingga penelitian ini berfokus pada miskonsepsi yang terjadi pada mahasiswa dilihat dari proses mengkonstruksi bukti.

Berdasarkan paparan di atas rumusan masalah dalam penelitian ini adalah bagaimana miskonsepsi mahasiswa pada konsep himpunan ditinjau dari kemampuannya dalam mengkonstruksi bukti. Tujuan dari penelitian ini adalah untuk mendeskripsikan miskonsepsi mahasiswa pada konsep himpunan ditinjau dari kemampuannya dalam mengkonstruksi bukti.

\section{METODE PENELITIAN}

Untuk menjawab rumusan serta tujuan penelitian yaitu mendiskripsikan miskonsepsi mahasiswa pada konsep himpunan ditinjau dari kemampuannya dalam mengkonstruksi bukti, penelitian ini didesain menggunakan penelitian deskriptif dengan pendekatan kualitatif dengan tahapan 1) studi pendahuluan, 2) perencanaan, 3) pelaksanaan. Subjek dalam penelitian ini adalah empat mahasiswa yang dipilih berdasarkan kategori kemampuannya dalam mengkonstruksi suatu bukti pada teorema yang ada pada materi himpunan. Kategori yang dimaksud adalah (1) general argument yang berarti mengkonstruksi bukti melalui pengurutan pernyataan yang mengacu pada semua kasus yang sebelumnya, (2) invalid general argument yaitu proses pembuktian masih lemah, (3) empirical argument yaitu proses pembuktian menggunakan beberapa kasus yang sesuai, dan (4) non genuine argument dengan hanya sebatas mempercayai pernyataan. Masing-masing subjek mewakili satu kategori kemampuan mengkonstruksi bukti.

Teknik pengumpulan data adalah dengan pemberian tes dan wawancara. Tujuan dari tes dan wawancara ini adalah untuk mendapatkan data terkait miskonsepsi yang siswa alami. Berdasarkan hal tersebut instrumen yang digunakan dalam penelitian ini adalah lembar tes dan pedoman wawancara. Tes berisi soal yang berkaitan dengan konsep dasar himpunan yang berhubungan dengan teorema yang dibuktikan mahasiswa pada tes awal (penentuan subjek) agar lebih terlihat miskonsepsi yang terjadi pada mahasiswa. Teknik analisis data terdiri dari tiga tahapan yaitu (1) reduksi data, (2) penyajian data, dan (3) penarikan kesimpulan. Reduksi data adalah memilih data primer yaitu data yang dapat memaparkan dengan jelas miskonsepsi yang siswa alami, untuk selanjutnya disajikan dalam bentuk deskripsi. Penarikan kesimpulan didasarkan pada hasil dari data yang telah disajikan. 
DOI: https://doi.org/10.24127/ajpm.v10i3.3735

\section{HASIL DAN PEMBAHASAN}

Berikut disajikan hasil pengerjaan tes masing-masing subjek ditinjau dari kriteria dalam mengkonstruksi bukti.

\section{Subjek General Argument}

Miskonsepsi pada subjek dengan kriteria pembuktian general argument terlihat pada Gambar 1.

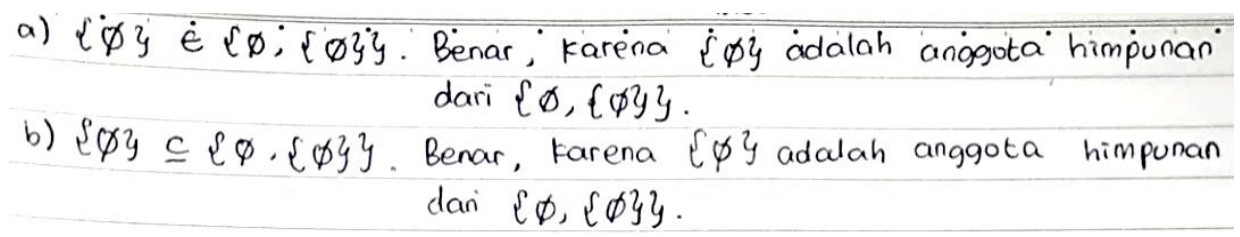

Gambar 1. Hasil pekerjaan subjek general argument

Berdasarkan Gambar 1 miskonsepsi yang dialami mahasiswa ditunjukkan dengan adanya pengertian yang tidak akurat terkait konsep subset Mahasiswa memberikan alasan yang sama untuk menentukan nilai kebenaran dari dua pernyataan yang berbeda yaitu $\{\varnothing\} \in\{\varnothing,\{\varnothing\}\} \quad$ dan $\quad\{\varnothing\} \subseteq\{\varnothing,\{\varnothing\}\}$. Konsep subset dan anggota himpunan jelas berbeda acuannya. Hal inilah yang menyebabkan mahasiswa ini terindikasi mengalami miskonsepsi pada konsep subset. Padahal dalam proses mengkonstuksi bukti yang berhubungan dengan konsep subset, mahasiswa ini tergolong kategori general argument yaitu membuktikan dengan tepat, kuat dan logis. Berikut petikan wawancara terhadap subjek.

Dosen : Apakah soal a dan $b$ merupakan dua soal yang sama?

Subjek : Tidak Bu

Dosen : Perbedaannya terletak dimana?

Subjek : Terletak pada simbolnya. Untuk soal a menggunakan simbol $\epsilon$ yang berarti anggota himpunan, untuk soal $b$ menggunakan simbol $\subseteq$ yang berarti subset.

Dosen : Bagaimana Anda menjawab soal a tersebut?

Subjek : Untuk soal a, pernyataan $\{\varnothing\} \in\{\varnothing,\{\varnothing\}\} \quad$ adalah benar. Karena himpunan kosong merupakan anggota dari $\{\varnothing,\{\varnothing\}\}$.

Dosen : Coba perhatikan kembali soal a, apakah memang benar simbol $\{\varnothing\}$ disebut himpunan kosong?

Subjek : Benar pak. (sambil menunjuk Ø)

Dosen : Bagaimana Anda menjawab soal b?

Subjek : Berdasarkan definsi subset, yaitu himpunan $A$ subset dari himpunan $B$ jika semua anggota himpunan $A$ berada pada himpunan B. terlihat pada pernyataan tersebut $\{\varnothing\}$ berada pada himpunan $\{\varnothing,\{\varnothing\}\}$. Jadi pernyataan tersebut benar.

Hasil wawancara di atas mendukung dugaan terjadinya miskonsepsi pada konsep subset yang berasal dari hasil tes mahasiswa. Temuan miskonsepsi lain berdasarkan wawancara tersebut adalah terkait konsep himpunan kosong dimana mahasiswa menyebutkan bahwa simbol $\{\varnothing\}$ bermakna himpunan kosong. Penafsiran konsep himpunan kosong yang tidak sesuai dengan makna konsep himpunan kosong itu sendiri. 


\section{Subjek invalid general argument}

Adapun hasil jawaban soal tes dari subjek invalid general argument terdapat pada Gambar 2.

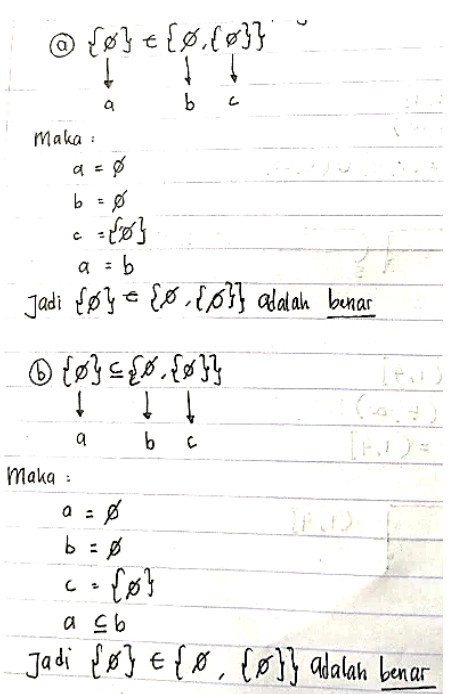

Gambar 2. Hasil pekerjaan subjek invalid general argument

Berdasarkan Gambar 2 mahasiswa dengan kriteria invalid general argument terlihat mengalami miskonsepsi pada konsep anggota himpunan. Kesalahan konsep anggota himpunan terlihat pada bagian a) yaitu ketika mahasiswa memisalkan unsur a dengan $\varnothing$. Padahal simbol $\in$ bermakna unsur. Seharusnya unsur yang dimaksud adalah $\{\varnothing\}$. Berdasarkan hal tersebut tampak bahwa mahasiswa belum akurat dalam memaknai konsep anggota himpunan. Selain pada konsep anggota himpunan, miskonsepsi juga terjadi pada konsep subset. Terlihat ketika subjek menuliskan kesimpulan $\mathrm{a} \subseteq \mathrm{b}$. Padahal b merupakan salah satu anggota dari himpunan $\{\varnothing,\{\varnothing\}\}$. Sehingga kesimpulan $\mathrm{a} \subseteq \mathrm{b}$ belum menjawab permasalahan. Hal ini didukung dengan hasil wawancara terhadap subjek invalid general argument berikut ini.

Dosen : Bagaimana Saudara menyelesaikan permasalahan a?

Subjek : Agar saya tidak bingung, saya melakukakn pemisalan seperti ini Bu (menunjukkan pemisalah yang ditulis pada lembar jawab). Misal saya menyebut $x \in A$ berarti $x$ berada di A. Nah karena unsur $a=\varnothing, b=\varnothing$ dan $a=b$ bearti pernyataan a benar.

Dosen : Kenapa $a=\varnothing$ ?

Subjek : Karena anggota dari himpunan diruas kiri Bu $(\{\varnothing\}) \quad$ karena yang ditanyakan adalah elemen.

\section{Subjek Empirical Argument}

Gambar 3 menyajikan hasil pekerjaan subjek dengan kriteria mengkornstruksi bukti empirical argument.

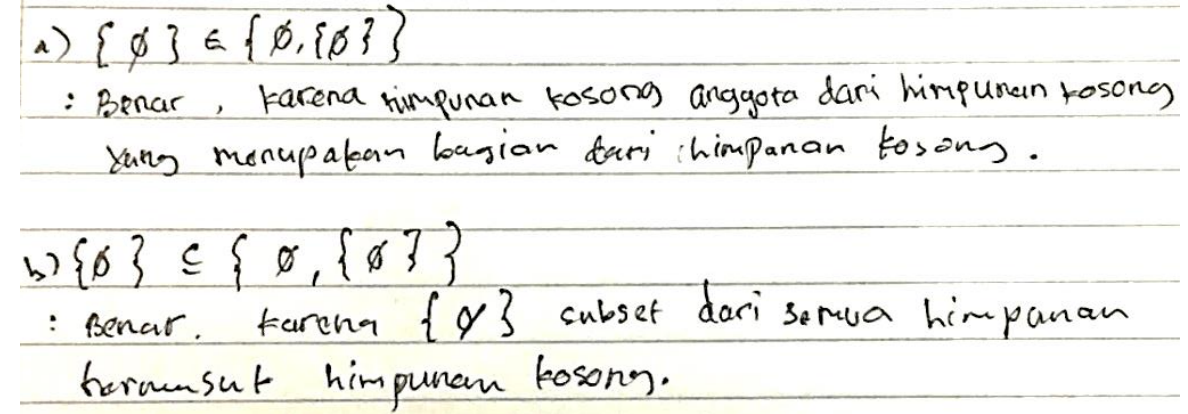

Gambar 3. Hasil pekerjaan subjek empirical argument 
DOI: $\underline{\text { https://doi.org/10.24127/ajpm.v10i3.3735 }}$

Data terjadinya miskonsepsi yang terlihat pada hasil pekerjaan mahasiswa tersebut berkaitan dengan konsep himpunan, himpunan kosong, anggota, dan subset. Miskonsepsi pada konsep himpunan dan himpunan kosong terlihat ketika mahasiswa menyebutkan bahwa $\{\varnothing\}$ dan $\{\varnothing,\{\varnothing\}\}$ sebagai himpunan kosong. Hal ini memperlihatkan bahwa mahasiswa belum tepat menghubungkan konsep himpunan dengan konsep himpunan kosong. Miskonsepsi pada konsep anggota himpunan terjadi ketika mahasiswa tersebut belum tepat dalam mendiskripsikan simbol $\{\varnothing\} \in\{\varnothing,\{\varnothing\}\}$. Mahasiswa tidak menyadari bahwa deskripsi tersebut tidak sesuai dengan kondisi pernyataan yang diberikan. Hal ini menunjukkan bahwa mahasiswa mengalami kebingungan dalam menyatakan simbol atau konsep anggota himpunan. Pada konsep subset, miskonsepsi terlihat pada ketika mahasiswa menyebutkan kebenaran dari pernyataan $\quad\{\varnothing\} \subseteq\{\varnothing,\{\varnothing\}\}$. Subjek memberikan pengertian yang tidak akurat terkait pengertian konsep subset dengan hanya mneyebutkan "subset" tanpa menggunakan makna subset itu sendiri. Cuplikan wawancara berikut mendukung indikasi miskonsepsi yang diperoleh dari data hasil tes.

Dosen : Coba jelaskan bagaimana cara Anda menjawab soal bagian a?

Subjek : Pernyataan $\quad\{\varnothing\} \in\{\varnothing,\{\varnothing\}\}$ benar karena himpunan $\{\varnothing,\{\varnothing\}\}$ adalah himpunan yang isinya simbol himpunan kosong. Jadi $\{\varnothing,\{\varnothing\}\}$ bisa disebut sebagai himpunan kosong. Jadi benar jika himpunan kosong merupakan anggota himpunan $\{\varnothing,\{\varnothing\}\}$.

\section{Dosen : Bagaimana dengan soal bagian b? \\ Subjek : Ya karena ini (menunjuk $\{\varnothing\})$ berada pada himpunan ini (menunjuk $\{\varnothing,\{\varnothing\}\})$ berarti pernyataan tersebut benar.}

Berdasarkan hasil wawancara di atas, dugaan miskonsepsi yang dipaparkan berdasarkan hasil tes tulis adalah benar. Mahasiswa mengalami miskonsepsi pada konsep himpunan, himpunan kosong, anggota himpunan dan subset.

\section{Subjek Non Genuine Argument}

Pada subjek kriteria non genuine argument miskonsepsi terjadi pada konsep subset. Lebih jelas Gambar 4 memaparkan hasil tes tulis mahasiswa dengan krtieria mengkonstruksi bukti non genuine argument.

\begin{tabular}{|c|}
\hline a. $\{\phi\} \in\{\varnothing,\{\varnothing\}\}$ \\
\hline Benar, Karena $\{\not\}$ termasule element \\
\hline dari $\{\varnothing,\{\varnothing\}\}$. \\
\hline 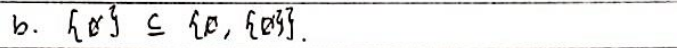 \\
\hline Salah, definisi subset $A \subseteq B$ jika \\
\hline dan harya jika $(\forall \forall)(u \in A \Rightarrow \psi \in B)$ \\
\hline Dimana, misal $A=\{\phi\}$ dan $B=\{\phi,\{\phi\}\}$. \\
\hline U ataul elemen di A tidak ada di $B$. Beginupun \\
\hline sebalikn-la elemen di B tidak adol diA. \\
\hline Maka tiden dikatakan 'subset' $(\leq)$. \\
\hline $\begin{array}{c}\text { Gambar 4. Hasil pekerjaan subjek non } \\
\text { genuine argument }\end{array}$ \\
\hline
\end{tabular}

Berdasarkan Gambar 3 tersebut, subjek non genuine argument mengalami miskonsepsi pada konsep anggota himpunan. Hal ini terlihat dari pernyataan mahasiwa pada bagian $b$ yang menyebutkan bahwa "elemen di $\mathrm{A}$ tidak ada di B". Pernyataan ini mengindikasikan bahwa mahasiswa mengalami miskonsepsi terkait konsep anggota himpunan. Jelas bahwa $\{\varnothing\}$ 
merupakan himpunan yang memiliki anggota $\varnothing$ dimana $\varnothing$ berada pada $\{\varnothing,\{\varnothing\}\}$. Selain konsep anggota himpunan, miskonsepsi terjadi pada konsep logika matematika lebih tepatnya pada konsep negasi pada iimplikasi. Pada hasil tersebut mahasiswa menyimpulkan "bukan subset" dengan alasan himpunan di A tidak ada di $\mathrm{B}$ dan sebaliknya himpunan di B tidak ada di A.

Berikut hasil wawancara dengan subjek non genuine argument.

$\begin{array}{ll}\text { Dosen : } & \text { Bagaimana Anda } \\ & \text { menentukan kebenaran dari } \\ & \text { pernyataan bagian b? } \\ \text { Subjek : } & \text { Sesuai dengan definisi } \\ & \text { subset yang telah saya } \\ & \text { sebutkan, karena }\{\varnothing\} \text { tidak } \\ & \text { ada di }\{\varnothing,\{\varnothing\}\} \text { dan } \\ & \text { sebaliknya. Sehingga }\{\varnothing\} \\ & \text { bukan subset dari }\{\varnothing,\{\varnothing\}\} \\ \text { Dosen }: & \text { Oh, apakah benar begitu } \\ & \text { cara menentukan "bukan } \\ & \text { subset"? }\end{array}$

Subjek : Benar. saya menentukan negasi yang berasal dari definisi subset yang berbentuk iimplikasi. Negasi dari $p \rightarrow q$ adalah $\neg p \rightarrow \neg q$.

Dosen : Di hasil tes ini Anda menyebutkan $A=\{\varnothing\}$ dan $B=\{\varnothing,\{\varnothing\}\}$ dimana elemen di A tidak ada di $B$. mengapa demikian?

Subjek : Anggota dari himpunan A adalah himpunan kosong. Kalau himpunan kosong, jelas tidak memiliki anggota sehingga tidak dapat berada di himpunan lain termasuk himpunan $B$.

Hasil wawancara di atas terlihat bahwa selain mengalami miskonsepsi pada konsep anggota himpunan dan negasi pada implikasi, mahasiswa juga mengalami miskonsepsi pada konsep himpunan kosong.

Berdasarkan paparan dari hasil penelitian di atas, meskipun (Viseu, Menezes, Fernandes, Gomes, \& Martins, 2017) menyatakan bahwa kemampuan mengkonstruksi bukti dapat digunakan sebagai modal utama dalam memverifikasi nilai kebenaran suatu pernyataan matematis, pernyataan ini tidaklah selalu benar. Terlihat dari subjek dengan kriteria mengkonstruksi bukti level tinggi yaitu general argument yang masih mengalami miskonsepsi. Hal ini menunjukkan adanya ketidaksingkronan antara proses pembuktian yang dilakukan dengan ketepatan pemaknaan konsep. Pendefinisian subset yang mengacu pada anggota himpunan merupakan bukti bahwa adanya ketidak akuratan konsep subset yang dimaknai oleh mahasiswa. Selain itu adanya ketidak sesuaian penafsiran makna simbol himpunan kosong juga merupakan salah satu ciri dari terjadinya miskonsepsi. Sejalan dengan (Sheu et al., 2013) yang menyatakan bahwa adanya perbedaan mendasar antara struktur sistematik dan struktur pengetahuan adalah indikasi terjadinya miskonsepsi.

Diawal pengerjaannya, subjek invalid general argument menggunakan pemisalan untuk membantu dalam menentukan nilai kebenaran suatu pernyataan. (Murphy et al., 2020) menyatakan bahwa salah satu teknik identifikasi masalah matematika adalah dengan pemisalan variabel. Meskipun pemisalan ini dapat membantu, tetapi pemisalan harus tepat. Berdasarkan hasil wawancara, pemisalan yang dilakukan subjek tidak tepat. Ketidaktepatan ini mengindikasikan bahwa mahasiswa belum akurat dalam 
memaknai konsep anggota himpunan dan subset dimana keduanya memiliki perbedaan acuan.

Miskonsepsi pada konsep himpunan, himpunan kosong, anggota himpunan, dan subset yang terjadi pada subjek empirical argument berhubungan dengan pemaknaan simbol yang kurang tepat. Pemaknaan simbol yang kurang tepat ini dapat mengakibatkan ketidaksesuaian menghubungkan dalam koneksikan suatu konsep dengan konsep lain (Orrantia et al., 2019). Dalam kasus ini subjek kebingungan dalam menghubungkan konsep himpunan dan himpunan kosong.

Dilihat dari proses mengkonstruksi bukti, subjek dengan kriteria non genuine argument merupakan subjek yang tidak dapat memberikan bukti baik secara empiris maupun teoritis. Peluang terjadinya miskonsepsi pada subjek berkategori non genuine argument ini lebih besar dibandingkan dengan kriteria yang lain. (Viseu et al., 2017) menyatakan bahwa kemampuan mengkonstruksi bukti memegang peranan penting dalam membangun pengetahuan matematika terutama dalam penyelesaian masalah prosedural. Pemisalan yang dilakukan oleh subjek non genuine argument sudah tepat. Tetapi karena subjek mengalami ketidak tepatan dalam menafsirkan konsep anggota himpunan serta tidak dapat menghubungkan konsep negasi implikasi pada suatu definisi, maka subjek tersebut mengalami miskonsepsi.

Secara umum miskonsepsi terjadi pada semua kriteria dalam mengkonstruksi bukti. Miskonsepsi yang terjadi merupakan akibat dari ketidakakuratan konsep, penggunaan konsep yang salah, pemaknaan konsep yang tidak sesuai dengan makna sebenarnya, dan tidak dapat menghubungkan antar suatu konsep dengan konsep lainnya.

\section{KESIMPULAN DAN SARAN}

Ditinjau dari kriteria dalam proses mengkonstruksi bukti, hasil penelitian menunjukkan bahwa miskonsepsi terjadi pada semua kriteria. Pada kriteria general argument miskonsepsi yang tejadi adalah ketidaksesuaian penafsiran konsep himpunan kosong dengan makna konsep himpunan kosong yang sebenarnya serta ketidakakuratan konsep subset yang dipahami. Pada subjek invalid general argument mengalami miskonsepsi berupa ketidak akuratan dalam memahami konsep anggota himpunan dan subset. Miskonsepsi yang terjadi pada subjek empirical argument adalah ketidak tepatan dalam menghubungkan konsep himpunan dan himpunan kosong, ketidaktepatan dalam mendiskripsikan makna simbol himpunan kosong, dan ketidak akuratan pada konsep subset. Sedangkan pada subjek non genuine argument miskonsepsi berupa ketidak tepatan dalam menafsirkan konsep anggota himpunan serta tidak dapat menghubungkan konsep negasi implikasi pada definisi subset, dan ketidak tepatan dalam memaknai simbol himpunan kosong.

Beberapa saran lanjutan untuk penelitian ini adalah adanya penelitian lanjutan terkait penyebab terjadinya miskonsepsi pada subjek dengan kriteria general argument. Mengingat bahwa subjek dengan kriteria general argument merupakan subjek yang ditinjau dari proses pembuktiannya sudah valid tetapi masih mengalami miskonsepsi dalam menyelesaikan masalah prosedural. 
DOI: https://doi.org/10.24127/ajpm.v10i3.3735

\section{DAFTAR PUSTAKA}

Andriani, L. (2019). Analisis Kesalahan Mahasiswa Dalam Meyelesaikan Soal Himpunan di Program Studi Pendidikan Matematika UIN SUSKA RIAU. Jurnal Cendekia: Jurnal Pendidikan Matematika, 3(2), 550-562. https://doi.org/10.31004/cendekia.v $3 \mathrm{i} 2.146$

Arslan, H. O., Cigdemoglu, C., \& Moseley, C. (2012). A Three-Tier Diagnostic Test to Assess PreService Teachers' Misconceptions about Global Warming, Greenhouse Effect, Ozone Layer Depletion, and Acid Rain. International Journal of Science Education.

https://doi.org/10.1080/09500693.2 012.680618

Ay, Y. (2017). A Review of Research on the Misconceptions in Mathematics Education. Education Research Highlights in Mathematics, 21-31.

Aydin, S., Kahraman, K., Of, M., Türkerı, K., Mutlu, C., \& Kiliçarslan, İ. (2017). Teaching abstract mathematics in vocational schools: Teachers' views. Turkish Online Journal of Educational Technology, 2017(December Special Issue INTE), 15-19.

Cetner, M. (2016). Common Misconceptions in Mathematics: Strategies to Correct Them. In Mathematics Teaching in the Middle School.

Goldin-Meadow, S. (2015). From action to abstraction: Gesture as a mechanism of change. Developmental Review, 38, 167184.

https://doi.org/10.1016/j.dr.2015.07 .007

Hallett, D., Nunes, T., \& Bryant, P. (2010). Individual Differences in Conceptual and Procedural Knowledge When Learning
Fractions. Journal of Educational Psychology. https://doi.org/10.1037/a0017486

Hayati, R., \& Setyaningrum, W. (2019). Identification of Misconceptions in Middle School Mathematics Utilizing Certainty of Response Index. Journal of Physics: Conference Series, 1320(1). https://doi.org/10.1088/17426596/1320/1/012041

Inglis, M., \& Alcock, L. (2012). Expert and novice approaches to reading mathematical proofs. Journal for Research in Mathematics Education, 43(4). https://doi.org/10.5951/jresemathed uc.43.4.0358

Kolitsoe Moru, E., \& Qhobela, M. (2013). Secondary school teachers' Pedagogical content knowledge of some common student errors and misconceptions in sets. African Journal of Research in Mathematics, Science and Technology Education. https://doi.org/10.1080/10288457.2 013.848534

Lestyanto, L. M., Nasution, S. H., Tejo, E., Cahyowati, D., Kahfi, M. S., \& Malang, U. N. (2019). Kesalahan konstruksi konsep mahasiswa pada materi himpunan dan defragmentasi struktur berpikirnya. Jurnal Review Pembelajaran Matematika (Jrpm), 4(2), 128-142.

Lucariello, J., Tine, M. T., \& Ganley, C. M. (2014). A formative assessment of students' algebraic variable misconceptions. Journal of Mathematical Behavior, 33(1), 3041. https://doi.org/10.1016/j.jmathb.20 13.09.001

Lui, A. M., \& Bonner, S. M. (2016). Preservice and inservice teachers' knowledge, beliefs, and instructional planning in primary school mathematics. Teaching and 
DOI: https://doi.org/10.24127/ajpm.v10i3.3735

Teacher Education, 56, 1-13. https://doi.org/10.1016/j.tate.2016.0 1.015

Ma, L. (2010). Knowing and teaching elementary mathematics: Teachers' understanding of fundamental mathematics in China and the United States: Second Edition. In Knowing and Teaching Elementary Mathematics: Teachers' Understanding of Fundamental Mathematics in China and the United States: Second Edition. https://doi.org/10.4324/9780203856 345

Mejia-Ramos, J. P., \& Weber, K. (2014). Why and how mathematicians read proofs: Further evidence from a survey study. Educational Studies in Mathematics, 85(2). https://doi.org/10.1007/s10649013-9514-2

Murphy, P. E. L., Evans, T., Klymchuk, S., Novak, J., Stephens, J., \& Thomas, M. (2020). University STEM students' perceptions of creativity in non-routine problemsolving. ANZIAM Journal, 61, C152-C165.

https://doi.org/10.21914/anziamj.v6 $1 \mathrm{i} 0.15052$

Ningrum, R. W., Yulianti, M., Helingo, D. D. Z., \& Budiarto, M. T. (2018). Students' Misconceptions on Properties of Rectangles. Journal of Physics: Conference Series. https://doi.org/10.1088/17426596/947/1/012018

Ojose, B. (2015). Students' Misconceptions in Mathematics: Analysis of Remedies and What Research Says. 72, 30-34.

Orrantia, J., Muñez, D., Matilla, L., Sanchez, R., San Romualdo, S., \& Verschaffel, L. (2019). Disentangling the Mechanisms of Symbolic Number Processing in Adults' Mathematics and Arithmetic Achievement. Cognitive Science, 43(1). https://doi.org/10.1111/cogs.12711 Özdemir, A. Ş., Karaşan, S., \& Şahal, M. (2021). An examination of the relationship between secondary school students' abstract thinking skills, self-efficacy perceptions and attitudes towards mathematics. Participatory Educational Research, 8(2), 391-406. https://doi.org/10.17275/per.21.45.8 .2

Sheu, T.-W., Chen, T.-L., Tsai, C.-P., Tzeng, J.-W., Deng, C.-P., \& Nagai, M. (2013). Analysis of Students' Misconception Based on Rough Set Theory. Journal of Intelligent Learning Systems and Applications, 05(02), 67-83. https://doi.org/10.4236/jilsa.2013.5 2008

Steele, M. D., \& Rogers, K. C. (2012). Relationships Between Mathematical Knowledge for Teaching and Teaching Practice: The Case of Proof. Journal of Mathematics Teacher Education. https://doi.org/10.1007/s10857012-9204-5

Stylianides, A. J., \& Stylianides, G. J. (2009). Proof constructions and evaluations. (March), 237-253. https://doi.org/10.1007/s10649009-9191-3

Tang, W. L., Tsai, J. T., \& Huang, C. Y. (2020). Inheritance coding with gagné-based learning hierarchy approach to developing mathematics skills assessment systems. Applied Sciences (Switzerland), 10(4). https://doi.org/ 10.3390/app10041465

Viseu, F., Menezes, L., Fernandes, J. A., Gomes, A., \& Martins, P. M. (2017). Conceptions of basic education teachers about math proof: Influence of professional experience. Bolema - Mathematics Education Bulletin, 31(57), 430453. https://doi.org/10.1590/1980$4415 \mathrm{v} 31 \mathrm{n} 57 \mathrm{a} 21$ 